\title{
食事に由来する $N$-ニトロソ化合物の一日撕取量
}

(昭和 59 年 10 月 24 日受理)

\author{
佐藤昭男*木 木寬* \\ 鈴木幸夫* 河村太郎*
}

\section{Daily Intake of $N$-Nitroso Compounds in Foodstuffs}

\author{
Akio Satoh, Hiroshi Kikawa, Yukio Suzuki and Taro Kawamura
}

(Yokohama City Institute of Health: 2-17, Takigashira

1-chome, Isogo-ku, Yokohama, Japan)

Recently considerable interest has been focussed on $N$-nitroso compounds because of their potent carcinogenicity and widespread distribution in foods, and this stimulated us to investigate the daily intake of $N$-nitroso compounds through the market-basket method and the duplicate portion method. The daily intake of $N$-nitrosodimethylamine was found to be $0.054 \sim 0.087 \mu \mathrm{g} /$ day (market-basket method) and $0.52 \mu \mathrm{g} /$ day (duplicate portion method) and no $N$-nitrosodiethylamine was detected.

The effect of heating and incubation in artificial gastric juice on the formation of $N$. nitrosodimethylamine in food was also examined. It was found that the $N$-nitrosodimethylamine content in a food mixture of fish and vegetables increased 6 times after heating as compared with that before heating, and it increased 2-fold on incubation in artificial gastric juice.

(Received October 24, 1984)

Key words: $N$-ニトロソ化合物 $N$-nitroso compound; 亜硝酸 nitrite; ニトロソアミン nitrosamine; マーケットバスケット方式 market-basket method; 陰膳方式 duplicate portion method; ニトロソジメチルアミン dimethylnitrosamine; ニトロソジェチルアミン diethylnitrosamine; 一日摂取量 daily intake; ジメチルアミン dimethylamine

\section{まえがき}

$N-$ ニロソ化合物は環境中や食品中に広く分布し， しかも数多くの動物種に強い発ガン作用を示す物質とし て 1962 年に Druckrey ら1によって最初に報告された.

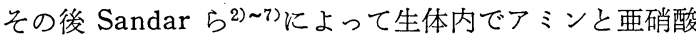
からニトロソアミンが生成することが報告されて以来, 食品衛生学領域において注目を集めている. この $N$-ニ トロソ化合物の摂取量について, 個々の食品の分析值に 基づく机上計算方式による推定はいくつかなされてい る $^{8), 9)}$.

そこで著者らは日本人が日常の食事からどの程度， $N$-ニトロソ化合物を摂取しているかについて，マーヶ ットバスケット方式及び陰膳方式を用いて調查を行っ た. また，N-ニトロソ化合物の前駆物質を多く含む食品

* 横浜市衛生研究所：横浜市磯子区滝頭 1-2-17
を食べ合せた場合を想定して人工胃液中で $N$-ニトロソ 化合物がどの程度生成するか, あるいは食品の加熱によ り $N$-ニトロソ化合物がどの程度生成するかについても 前記方式の試料を用いて実験を行ったので報告する.

\section{実験方法}

1. 試料

1) 日常食品からの $N$-ニトロソジメチルアミン (NDMA), $N$-ニトロソジェチルアミン (NDEA) の一日摂 取量

i) マーケットバスケット方式：国民栄養調査の関東 I 地区 (東京都, 神奈川県, 埼玉県, 千葉県) のデータ に基づき日常食品の構成と数量を88食品について定め, それぞれの必要量を昭和 57 年 3 月及び 5 月に横浜市内大 手スーパーより購入した後，それを食品の性質に従って 第 I 群 (米加工品類) 〜第 XIII 群（加工食品類）に群別 
した (Table 2). 次に調理を要するものは調理をした後, 各群毎に食品を均一に混合して分析試料とした。

ii）陰膳方式：昭和57年 6 月 21 日～27日に横浜市内の 全尞制学校 (施設 $M)$, 老人ホーム (施設 I) の 2 施設及 び同21日〜24日に一般家庭（当所職員）で採取した一人 一日分の食事 (朝食, 昼食, 夕食) をそれぞれ均一に混 合して分析試料とした.

2) 人工胃液中における NDMA, NDEA の生成 前述 1)-i）で調製した食品群のらち硝酸塩を多く含む 緑色野菜類 (VII 群) ととの他の野菜, きのこ海草類 (VIII 群)，またジメチルアミン (DMA) を多く含む魚 介類 (X 群) と卵肉類 (XI 群) を選び各群 0.15 日分を 分取して Table 4 に示す組み合せをつくり，それぞれ 均一に混合した。 また 1)-ii）で採取した朝食, 昼食, 夕 食を食事毎に均一に混合し，その $50 \mathrm{~g}$ を分取した。次 にこれらに同量の人工胃液 ${ }^{10}$ を加え $37^{\circ}$ で 2 時間振とう 後，炭酸カリウム $2 \mathrm{~g}$ を加光分析試料とした.

3）食品の加熱による NDMA，NDEA の生成
前述 1)-i）で調製した緑色野菜類，その他の野菜，き のこ海草類, 魚介類, 卵肉類の試料, 各 0.15 日分を分 取し Table 6 に示す組合せをつくり，均一に混合した 後, $90^{\circ}$ で90分間放置後分析試料とした.

\section{2. 試薬}

水酸化カリウム, 炭酸カリウム, 塩化ナトリウム, 塩

Table 1. Operating Conditions of TEA-GC

\begin{tabular}{ll}
\hline \hline Instrument & $\begin{array}{l}\text { Shimadzu 6A type equipped } \\
\text { with TEA }\end{array}$ \\
Column & Glass column 3 mm i.d. \\
& $1.5 \mathrm{~m}$ long \\
Liquid phase & $\begin{array}{l}\text { Versamid 900, 20\% (Chro- } \\
\text { mosorb W-AW, 100-120 }\end{array}$ \\
& mesh) \\
Injection temperature & $150^{\circ} \mathrm{C}$ \\
Column temperature & $110^{\circ} \mathrm{C}$ \\
Carrier gas & $\mathrm{Ar}, 60 \mathrm{ml} / \mathrm{min}$ \\
\hline
\end{tabular}

Table 2. Estimated Daily Intake of $N$-Nitroso Compounds (the Market-basket Method)

\begin{tabular}{|c|c|c|c|c|c|c|c|}
\hline \multirow{3}{*}{$\begin{array}{c}\begin{array}{c}\text { Sample } \\
\text { group }\end{array} \\
\text { I }\end{array}$} & \multirow{3}{*}{$\begin{array}{r}\begin{array}{r}\text { Food } \\
\text { item }\end{array} \\
\text { Rice }\end{array}$} & \multirow{2}{*}{\multicolumn{2}{|c|}{$\begin{array}{c}\text { Consumption } \\
\text { (g/day) }\end{array}$}} & \multicolumn{2}{|c|}{ NDMA } & \multicolumn{2}{|c|}{ NDEA } \\
\hline & & & & \multirow{2}{*}{$\begin{array}{l}\begin{array}{l}\text { Conc. } \\
\text { (ppb) }\end{array} \\
<0.2 \\
<0.2\end{array}$} & \multirow{2}{*}{$\begin{array}{c}\begin{array}{c}\text { Intake } \\
(\mu \mathrm{g} / \text { day })\end{array} \\
- \\
-\end{array}$} & \multirow{2}{*}{$\begin{array}{l}\begin{array}{l}\text { Conc. } \\
\text { (ppb) }\end{array} \\
<0.2 \\
<0.2\end{array}$} & \multirow{2}{*}{$\begin{array}{c}\begin{array}{c}\text { Intake } \\
(\mu \mathrm{g} / \text { day })\end{array} \\
- \\
-\end{array}$} \\
\hline & & $\begin{array}{l}\mathrm{A} \\
\mathrm{B}\end{array}$ & $\begin{array}{l}410 \\
415\end{array}$ & & & & \\
\hline II & $\begin{array}{l}\text { Cereal } \\
\text { Grain } \\
\text { Potato }\end{array}$ & $\begin{array}{l}\mathrm{A} \\
\mathrm{B}\end{array}$ & $\begin{array}{l}191 \\
203\end{array}$ & $\begin{array}{l}<0.2 \\
<0.2\end{array}$ & - & $\begin{array}{l}<0.2 \\
<0.2\end{array}$ & - \\
\hline III & $\begin{array}{l}\text { Sugar } \\
\text { Cake }\end{array}$ & $\begin{array}{l}\mathrm{A} \\
\mathrm{B}\end{array}$ & $\begin{array}{l}38.5 \\
37.9\end{array}$ & $\begin{array}{l}<0.2 \\
<0.2\end{array}$ & - & $\begin{array}{l}<0.2 \\
<0.2\end{array}$ & - \\
\hline IV & $\begin{array}{l}\text { Fat } \\
\text { Oil }\end{array}$ & $\begin{array}{l}\mathrm{A} \\
\mathrm{B}\end{array}$ & $\begin{array}{l}21.4 \\
20.1\end{array}$ & $\begin{array}{l}<0.2 \\
<0.2\end{array}$ & - & $\begin{array}{l}<0.2 \\
<0.2\end{array}$ & - \\
\hline $\mathrm{V}$ & $\begin{array}{l}\text { Bean } \\
\text { Product }\end{array}$ & $\begin{array}{l}\mathrm{A} \\
\mathrm{B}\end{array}$ & $\begin{array}{l}63.3 \\
62.2\end{array}$ & $\begin{array}{l}<0.2 \\
<0.2\end{array}$ & - & $\begin{array}{l}<0.2 \\
<0.2\end{array}$ & - \\
\hline VI & Fruit & $\begin{array}{l}\mathrm{A} \\
\mathrm{B}\end{array}$ & $\begin{array}{l}169 \\
164\end{array}$ & $\begin{array}{l}<0.2 \\
<0.2\end{array}$ & - & $\begin{array}{l}<0.2 \\
<0.2\end{array}$ & - \\
\hline VII & $\begin{array}{l}\text { Vegetable } \\
\text { (Green) }\end{array}$ & $\begin{array}{l}\mathrm{A} \\
\mathrm{B}\end{array}$ & $\begin{array}{l}45.2 \\
52.6\end{array}$ & $\begin{array}{l}<0.2 \\
<0.2\end{array}$ & - & $\begin{array}{l}<0.2 \\
<0.2\end{array}$ & - \\
\hline VIII & $\begin{array}{l}\text { Vegetable } \\
\text { (White) } \\
\text { Seaweed }\end{array}$ & $\begin{array}{l}\mathrm{A} \\
\mathrm{B}\end{array}$ & $\begin{array}{l}193 \\
208\end{array}$ & $\begin{array}{l}<0.2 \\
<0.2\end{array}$ & - & $\begin{array}{l}<0.2 \\
<0.2\end{array}$ & - \\
\hline IX & Beverage & $\begin{array}{l}\mathrm{A} \\
\mathrm{B}\end{array}$ & $\begin{array}{l}129 \\
150\end{array}$ & $\begin{array}{l}<0.2 \\
<0.2\end{array}$ & - & $\begin{array}{l}<0.2 \\
<0.2\end{array}$ & - \\
\hline$X$ & $\begin{array}{l}\text { Fin-fish } \\
\text { Crustacean } \\
\text { Molluscs }\end{array}$ & $\begin{array}{l}\mathrm{A} \\
\mathrm{B}\end{array}$ & $\begin{array}{l}62.9 \\
69.9\end{array}$ & $\begin{array}{l}0.70 \\
0.73\end{array}$ & $\begin{array}{l}0.044 \\
0.051\end{array}$ & $\begin{array}{l}<0.2 \\
<0.2\end{array}$ & - \\
\hline XI & $\begin{array}{l}\text { Meat } \\
\text { Egg }\end{array}$ & $\begin{array}{l}\mathrm{A} \\
\mathrm{B}\end{array}$ & $\begin{array}{l}99.3 \\
108\end{array}$ & $\begin{array}{l}0.39 \\
<0.2\end{array}$ & $\begin{array}{l}0.039 \\
-\end{array}$ & $\begin{array}{l}<0.2 \\
<0.2\end{array}$ & - \\
\hline XII & $\begin{array}{l}\text { Milk } \\
\text { Milk- } \\
\text { Product }\end{array}$ & $\begin{array}{l}\mathrm{A} \\
\mathrm{B}\end{array}$ & $\begin{array}{l}126 \\
136\end{array}$ & $\begin{array}{l}<0.2 \\
<0.2\end{array}$ & - & $\begin{array}{l}<0.2 \\
<0.2\end{array}$ & - \\
\hline XIII & $\begin{array}{l}\text { Cooked } \\
\text { Meal }\end{array}$ & $\begin{array}{l}\mathrm{A} \\
\mathrm{B}\end{array}$ & $\begin{array}{r}6.0 \\
14.2\end{array}$ & $\begin{array}{l}0.65 \\
0.20\end{array}$ & $\begin{array}{l}0.004 \\
0.003\end{array}$ & $\begin{array}{l}<0.2 \\
<0.2\end{array}$ & - \\
\hline & & $\begin{array}{l}\mathrm{A} \\
\mathrm{B}\end{array}$ & $\begin{array}{l}1554.6 \\
1640.9\end{array}$ & & $\begin{array}{l}0.087 \\
0.054\end{array}$ & & - \\
\hline
\end{tabular}

A: In March B: In May 
Table 3. Estimated Daily Intake of N-Nitroso Compounds (the Duplicate Portion Method)

\begin{tabular}{|c|c|c|c|c|c|c|}
\hline & \multirow{2}{*}{ Date } & \multirow{2}{*}{$\begin{array}{l}\text { Consumption } \\
\text { (g/day) }\end{array}$} & \multicolumn{2}{|c|}{ NDMA } & \multicolumn{2}{|c|}{ NDEA } \\
\hline & & & $\begin{array}{l}\text { Conc. } \\
\text { (ppb) }\end{array}$ & $\begin{array}{c}\text { Intake } \\
(\mu \mathrm{g} / \text { day })\end{array}$ & $\begin{array}{l}\text { Conc. } \\
(\mathrm{ppb})\end{array}$ & $\begin{array}{c}\text { Intake } \\
(\mu \mathrm{g} / \text { day })\end{array}$ \\
\hline \multirow{8}{*}{ Institution I } & $6 / 21$ & 1316 & 0.56 & 0.74 & $<0.2$ & - \\
\hline & 22 & 1258 & 0.81 & 1. 01 & $<0.2$ & - \\
\hline & 23 & 1142 & 0.57 & 0.65 & $<0.2$ & - \\
\hline & 24 & 1390 & 0.33 & 0.46 & $<0.2$ & - \\
\hline & 25 & 1426 & 0.81 & 1.15 & $<0.2$ & - \\
\hline & 26 & 1314 & $<0.2$ & - & $<0.2$ & - \\
\hline & 27 & 1290 & $<0.2$ & - & $<0.2$ & - \\
\hline & & \multicolumn{5}{|c|}{$0.57 \pm 0.42^{*}$} \\
\hline \multirow{8}{*}{ Institution $\mathrm{M}$} & $6 / 21$ & 1483 & $<0.2$ & - & $<0.2$ & - \\
\hline & 22 & 1978 & $<0.2$ & - & $<0.2$ & - \\
\hline & 23 & 1705 & 0.55 & 0.94 & $<0.2$ & - \\
\hline & 24 & 1750 & $<0.2$ & - & $<0.2$ & - \\
\hline & 25 & 1744 & 0.38 & 0.66 & $<0.2$ & - \\
\hline & 26 & 2085 & 0.47 & 0.98 & $<0.2$ & - \\
\hline & 27 & 1574 & $<0.2$ & - & $<0.2$ & 一 \\
\hline & & \multicolumn{5}{|c|}{$0.37 \pm 0.44^{*}$} \\
\hline \multirow{5}{*}{$\begin{array}{l}\text { Ordinary } \\
\text { home }\end{array}$} & $6 / 21$ & 1840 & 0.98 & 1.81 & $<0.2$ & - \\
\hline & 22 & 1609 & $<0.2$ & - & $<0.2$ & - \\
\hline & 23 & 1957 & $<0.2$ & - & $<0.2$ & - \\
\hline & 24 & 2229 & 0.41 & 0.91 & $<0.2$ & - \\
\hline & & \multicolumn{5}{|c|}{$0.68 \pm 0.76^{*}$} \\
\hline
\end{tabular}

*: Mean \pm S.D.

Table 4. Formation of Dimethylnitrosamine in Artificial Gastric Juice and Foods (the Market-basket Method)

\begin{tabular}{|c|c|c|c|c|}
\hline \multirow{3}{*}{ Mixed group* } & \multicolumn{4}{|c|}{ Daily intake ( $\mu \mathrm{g} / \mathrm{day})$} \\
\hline & \multicolumn{2}{|c|}{ March } & \multicolumn{2}{|c|}{ May } \\
\hline & Treated & None & Treated & None \\
\hline$(\mathrm{VII}+\mathrm{VIII})+(\mathrm{X})$ & 0.10 & 0.04 & 0.13 & 0.05 \\
\hline$(\mathrm{VII}+\mathrm{VIII})+(\mathrm{XI})$ & - & - & 0.08 & 0.04 \\
\hline$(\mathrm{VII}+\mathrm{VIII})+(\mathrm{X}+\mathrm{XI})$ & 0.22 & 0.09 & 0.11 & 0.05 \\
\hline
\end{tabular}

*: VII, Vegetable (green); VIII, Vegetable (white) and seaweed; X, Fin-fish, crustacean and molluscs; XI, Meat and egg

\section{酸：和光純薬工業 (株) 製試薬特級}

ジクロロメタン，無水硫酸ナトリウム：和光純薬工業 (株) 製残留農薬試験用

NDMA 及び NDEA 標準溶液：NDMA（和光純薬工 業(株)製 $\mathrm{GC}$ 用), NDEA (和光純薬工業 (株)製和光特 級)をジクロロメタンに溶解してそれぞれ $0.1,0.3$ 及
び $0.5 \mathrm{ppm}$ になるように調製した。

\section{3. 装置}

Thermal Energy Analyzer 付ガスクロマトグラフ： (株) 島津製作所製 GC-6 A

\section{4. 試験溶液の調製}

Yamamoto ら ${ }^{11)}$ の方法に準じて行った.

試料 $50 \mathrm{~g}$ を $1 \mathrm{~L}$ の蒸留フラスコにとり，精製水 150 $\mathrm{ml}$ と水酸化カリウム $30 \mathrm{~g}$ を加え水蒸気蒸留する. 受器 にあらかじめ $1 N$ 塩酸 $10 \mathrm{ml}$ を入れ冷却器の先端をこ の中に浸す. 受器中の液量が $200 \mathrm{ml}$ になったとき蒸留 をやめ, これを $500 \mathrm{ml}$ の分液漏斗に移し炭酸カリウム $20 \mathrm{~g}$ を加え, ジクロロメタン $200 \mathrm{ml}$ で 2 回抽出した. ジクロロメタン層は無水硫酸ナトリウムで脱水後, ロー タリーエバポレーターを用い $35^{\circ}$ 以下で $5 \sim 8 \mathrm{ml}$ まで 減圧濃縮し, さらに窒素気流下で $1 \mathrm{ml}$ に濃縮し試験溶 液とした.

\section{5. 定量操作}

試験溶液及び空試験溶液 $5 \mu 1$ を Thermal Energy Analyzer 付 GC に供し, Table 1 の条件で NDMA, NDEA を測定した。 また定量はピーク高による絶対検 
量線法により行った.

\section{結果及び考察}

1. 日常食品からの NDMA, NDEA の一日摂取量

1) マーケットバスケット方式

Table 2 に示したとおり NDMA は動物性食品群にの 又検出された. その值は魚介類 (X 群), 卵肉類 (XI 群), 加工食品類（XIII 群）でそれぞれ $0.70 \sim 0.73 \mathrm{ppb,}$ $0.39 \mathrm{ppb}, 0.2 \sim 0.65 \mathrm{ppb}$ と魚介類がわずかに高かった が，その合計一日摂取量は $0.087 \mu \mathrm{g}$ (3 月), $0.054 \mu \mathrm{g}$ (5月）と少なかった. 一方, NDEA はいずれの食品群 からも検出されなかった.

2) 陰膳方式

Table 3 に示したように NDMA の一日㩒取量は献立 内容によりかなりの差がみられ，動物性食品，特に魚を 使った献立に比較的多くみられた. その平均值は施設 I, 施設 $\mathrm{M}$, 一般家庭でそれぞれ $0.57 \mu \mathrm{g}, 0.37 \mu \mathrm{g}, 0.68 \mu \mathrm{g}$ と施設間及び一般家庭との間に， ほとんど差はみられな かった. しかしマーケットバスケット方式での調査結果 より高い值を示したが，これはマーケットバスケット方 式では食品群每に群別され, 動物性食品と野菜類が混合 されない状態で分析したのに対し, 陰膳方式ではこれら の食品が調理時から混合されているために NDMA が 生成したものと思われる．またこれらの值は著者らが昭 和56年度に病院の食事について延べ14日間にわたって調 査した結果の平均一日摄取量 $0.78 \mu \mathrm{g}$ とほぼ同様の值 であっだ.

今回の NDMA，一日摂取量調査結果はこれまでに机 上計算方式で算出されている日本人の平均一日摂取量 (1〜2 $\mu \mathrm{g})$ をかなり下まわっていた8). 一方, NDEA は いずれの献立からも検出されなかった。

\section{2. 人工胃液中における NDMA の生成}

NDMA の前駆物質を多く含む食品群のみを同時に摂 取した場合を想定して, 野菜類 (VII 群, VIII 群) と急 介類 (X 群) 及び卵肉類 (XI 群) を平均胃内容排出時間 の 2 時間, 人工胃液で処理した. その結果は Table 4 に 示したと和り野菜類と魚介類, 野菜類と魚介類に卵肉類 を混合したものから NDMA が検出され，その一日摂取 量は $0.10 \sim 0.22 \mu \mathrm{g}$ で各群毎に個別に分析した場合 (0.04 0.05 $\mu \mathrm{g})$ より高い傾向がみられた. しかし日常 の食生活では各食品群を同時に摂取しているため, 陰膳 方式で調製した試料の朝食，昼食，夕食を各食事ごとに 人工胃液で処理して分析した結果, Table 5 に示したと おり，NDMA の一日摂取量平均值は施設 I で $0.59 \mu \mathrm{g}$, 施設 $\mathrm{M}$ で $0.28 \mu \mathrm{g}$, 一般家庭で $0.93 \mu \mathrm{g}$ と,試料を直接 分析した場合とほぼ同様の值であった。なお,これらの 実験での反応溶液の $\mathrm{pH}$ は $2.1 \sim 4.2$ の範囲内で，い ずれも NDMA 生成に適していた.

* 第 19 回全国衛生化学技術協議会年会 (1982).
Table 5. Formation of Dimethylnitrosamine in Artificial Gastric Juice and Foods (the Duplicate Portion Method)

\begin{tabular}{|c|c|c|c|}
\hline & \multirow{2}{*}{ Date } & \multicolumn{2}{|c|}{ Intake ( $\mu \mathrm{g} /$ day $)$} \\
\hline & & Treated & None treated \\
\hline \multirow{8}{*}{ Institution I } & $6 / 21$ & 0.60 & 0.74 \\
\hline & 22 & 0.82 & 1.01 \\
\hline & 23 & 1.01 & 0.65 \\
\hline & 24 & 0.42 & 0.46 \\
\hline & 25 & 0.72 & 1.15 \\
\hline & 26 & 0.57 & $<0.3$ \\
\hline & 27 & $<0.3$ & $<0.3$ \\
\hline & & $0.59 \pm 0.30^{*}$ & $0.57 \pm 0.42^{*}$ \\
\hline \multirow{8}{*}{ Institution $\mathrm{M}$} & $6 / 21$ & 0.38 & $<0.3$ \\
\hline & 22 & $<0.3$ & $<0.3$ \\
\hline & 23 & $<0.3$ & 0.94 \\
\hline & 24 & $<0.3$ & $<0.3$ \\
\hline & 25 & 0.80 & 0.66 \\
\hline & 26 & 0.78 & 0.98 \\
\hline & 27 & $<0.3$ & $<0.3$ \\
\hline & & $0.28 \pm 0.35^{*}$ & $0.37 \pm 0.44^{*}$ \\
\hline \multirow{5}{*}{$\begin{array}{l}\text { Ordinary } \\
\text { home }\end{array}$} & $6 / 21$ & 2.28 & 1.81 \\
\hline & 22 & 0.35 & $<0.3$ \\
\hline & 23 & $<0.3$ & $<0.3$ \\
\hline & 24 & 1.09 & 0.91 \\
\hline & & $0.93 \pm 0.87^{*}$ & $0.68 \pm 0.75^{*}$ \\
\hline
\end{tabular}

*: Mean \pm S.D.

Table 6. Formation of Dimethylnitrosamine in Vegetable Foods and Fishes (included crustacean) or Meats (included egg) Mixture on Heating

\begin{tabular}{|c|c|c|c|c|}
\hline \multirow{3}{*}{ Mixed group* } & \multicolumn{4}{|c|}{ Daily intake ( $\mu$ g/day) } \\
\hline & \multicolumn{2}{|c|}{ March } & \multicolumn{2}{|c|}{ May } \\
\hline & Treated & None & Treated & None \\
\hline$(\mathrm{VII}+\mathrm{VIII})+(\mathrm{X})$ & 0.23 & 0.04 & 0.08 & 0.05 \\
\hline$(\mathrm{VII}+\mathrm{VIII})+(\mathrm{XI})$ & 0.03 & - & 0.03 & 0.04 \\
\hline$(\mathrm{VII}+\mathrm{VIII})+(\mathrm{X}+\mathrm{XI})$ & 0.14 & 0.09 & 0.25 & 0.05 \\
\hline
\end{tabular}

*: VII, Vegetable (green); VIII, Vegetable (white) and seaweed; X, Fin-fish, crustacean and molluscs; XI, Meat and egg

以上のように DMA を多く含む食品群と亜硝酸塩を 多く含む食品群が実験開始まで混合されないマーケット バスケット方式の試料を用いた人工胃液中での実験では NDMA の増加が認められたが，試料の調製時からすべ ての食品が混合されている陰膳方式では NDMA の増 加は認められなかった．従って日常の食事に含まれる程 
度の DMA 及び亜硝酸塩の存在では $N$-ニトロソ化反 応の至適 $\mathrm{pH}$ (3.4) 条件下でも，ほとんど反応が進まな いためと思われる.ささらに今回の結果は酒井ら ${ }^{6)}$ の報告 しているウサギを用いた実験で覀硝酸ナトリウムをとト の平均一日摂取量の 1,400 倍 $(100 \mathrm{mg} / \mathrm{kg})$ ，また DMA についても $100 \mathrm{mg} / \mathrm{kg}$ と大量投与した場合でも NDMA の生成が $0.1 \%$ に満たなかったことと一致す る.

これらのことから唾液によって供給される亜硝酸 (塩) を考慮しても胃中での $N$-ニトロソ化はほとんど起こら ないと言えよう。

\section{3. 食品の加熱による NDMA, NDEA の生成}

$N$-ニトロソ化合物の前駆物質を多く含む食品群だけ を混合して調理時の条件に近い $90^{\circ}$ で加熱を行った場 合のN-ニトロソ化合物の生成を調査した結果, Table 6 に示したように 5 月に調査した野菜類 (VII 群, VIII 群) と卵肉類 (XI 群) を混合した場合を除き，か なりの NDMA の生成が認められた. 特に 3 月に調查し た野菜類と魚介類 (X 群) を混合後加熱した場合には検 体をそのまま分析した場合の一日摂取量 $0.04 \mu \mathrm{g}$ に対 し, 約 6 倍の $0.23 \mu \mathrm{g}$ に增加した。

この実験は DMA と巠硝酸塩を多量に含む食品だけ を混合後, 通常の加熱調理時間よりもかなり長く加熱す るという特殊な条件で行っているが，それでも NDMA の一日摂取量は最大で $0.25 \mu \mathrm{g}$ と低い值であった。

\section{まとめ}

日常食品からの NDMA の一日摂取量は 0.054〜 $1.81 \mu \mathrm{g} / \mathrm{day}$ でこれまでに推定されてきた值（1２ $\mu \mathrm{g} /$ day $)^{8,9)}$ を下まわっていた。 また，人工胃液を用いた実 験から日常の食事に含まれる程度の亜硝酸塩及び DMA の存在では $N$-ニトロソ化に好適な強酸性の胃中におい ても NDMA の生成はほとんぞ無いと考えられる. NDMA の前駆物質を多く含む食品だけを混合後加熱し
た場合の NDMA の一日摂取量は 2〜6 倍に増加した。

\section{謝辞}

本研究の実施にあたり有益な御助言をいただいた国立 衛生試験所副所長, 谷村顕雄博士ならびに TEA-GC に よる $N$ ・ ニトロソ化合物の分析に御協力いただいた同食 品添加物部の諸氏に深謝いたします。なお，本研究は昭 和 57 年度の厚生省がん研究助成金によるものである。 た本研究の一部は第 19 回全国衛生化学技術協議会年会 (1982年 9 月，京都）において発表した.

文献

1) Druckrey H., Preussmann R.: Naturwissenschaften. 49, 111 112 (1962).

2) Sandar, J.: Arch. Hyg. 151, 22 (1967).

3) Sandar, J., Schweinsberg, F., Menz, H.: Hoppe-Seyler's Z. Physiol. Chem. 349, 1691 1697 (1968).

4) Sandar, J., Seif, F.: Arzneim. Forsch. 19, 1091 (1969).

5) Sen, N. P., Smith, D. C., Schwinghamer, L.: Fd. Cosmet. Toxicol. 7, 301 307 (1969).

6) 酒井綾子, 谷村顕雄：食衛誌. 12, $170 \sim 176$ (1971).

7) Lane, R. P., Bailey, M. E.: Fd. Cosmet. Toxicol. 11, 851 854 (1973).

8) Maki, T., Tamura, Y., Shimamura, Y., Naoi, Y.: Bull. Environm. Contam. Toxicol. 25, 257 261 (1980).

9) Spiegelhalder, B., Eisenbrand, G., Preussmann, R.: Oncology 37, 211 216 (1980).

10) “第十改正日本薬局方” p. 734 (1981).

11) Yamamoto, M., Yamada, T., Tanimura, A.: Fd. Cosmet. Toxicol. 18, 297 299 (1980). 